\title{
ADVANCING COASTAL ENGINEERING IN US HIGHWAYS
}

\author{
Scott L. Douglass, South Coast Engineers, scott@southcoastengineers.com \\ Joseph Krolak, Federal Highway Administration, Joseph.Krolak@dot.gov \\ Brian Beucler, Federal Highway Administration, Brian.Beucler@dot.gov \\ Bret M. Webb, University of South Alabama, bwebb@southalabama.edu
}

\section{SHORT ABSTRACT}

Transportation systems along the coast need integration of coastal engineering principles and practices in their planning, design, and operation. The Federal Highway Administration (FHWA), with statutory authority allowing consideration of "extreme events," develops technical engineering guidance and professional development training focused on highways in the coastal environment.

\section{ROADS AND BEACHES}

Two of America's great emotional love affairs are with roads and with beaches. Coastal highways are part of the fabric of society from California's Route 1 to Florida's A1A. It is estimated that there are roughly 60,000 miles of roadways in the 100-year coastal storm surge floodplain and over 1,000 bridges exposed to storm surge conditions with the present-day sea levels. This paper and presentation will summarize Federal Highway Administration (FHWA) efforts related to the issues this exposure presents. A primary goal is improved integration of coastal engineering principles and practices in the planning and design of coastal highways.

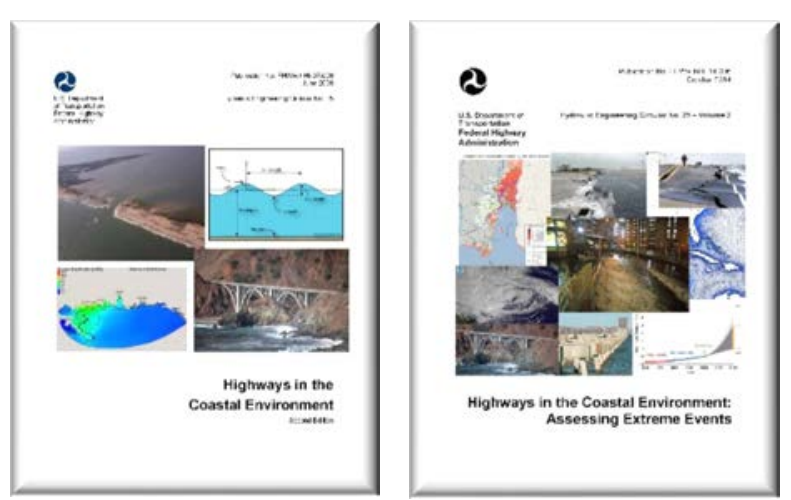

Figure 1. HEC-25: Highways in the Coastal Environment is FHWA's technical guidance manual for coastal highways and bridges. This manual presently is being revised to combine and update the two existing volumes into a single $3^{\text {rd }}$ edition.

\section{HIGHWAYS IN THE COASTAL ENVIRONMENT}

FHWA's Hydraulic Engineering Circular No. 25, or HEC25, "Highways in the Coastal Environment" ( $2^{\text {nd }}$ ed.) is a technical guidance manual for the analysis, planning, design and operation of highways in the coastal environment (FHWA 2008). The manual has three sections describing:

1. Background and Context

2. Principles of Coastal Science \& Engineering

3. Issues and Approaches in Coastal Highway Design

The target audience for the manual is transportation engineers and other transportation professionals as well as coastal engineers providing assistance and consultation to transportation agencies. There is an extensive glossary of coastal science and engineering terms. The third section of the manual (i.e., "Issues and Approaches in Coastal Highway Design") includes chapters on:

- Coastal Revetments for Wave Attack

- Roads in Areas of Receding Shorelines

- Highway Overwashing, and

- Coastal Bridges, including a method for estimating wave-induced loads on bridge decks

This manual is currently undergoing revisions and updates as described below.

\section{EXTREME EVENTS AND CLIMATE RESILIENCE}

The 2012 passage of MAP-21 provided FHWA with the statutory authority to consider extreme events, such as Hurricanes Sandy and Harvey, as well as researching climate variability. As a result, FHWA developed a second volume (See Figure 1) of HEC-25, "Highways in the Coastal Environment: Volume 2: Assessing Extreme Events" to provide guidance on quantitative methods for assessing the vulnerability of coastal roads and bridges to extreme events and climate change (FHWA 2014). The focus is quantifying exposure to sea level rise, storm surge, and waves considering climate change. This second volume incorporates sea level rise projections into storm surge and wave modeling. The manual presents specific approaches via three different "levels of effort," ranging from use of available data to numerical modeling. Chapters in HEC-25: Volume 2 include:

- Relevant Coastal Processes and Climate Change Impacts

- Risk, Vulnerability, and Adaptation

- Analysis Methods for Assessing Extreme Events and Climate Change, and

- Case Studies of Exposure and Vulnerability Assessments

Recent, related research on how to adapt to rising sea levels includes the interesting finding that one major US bridge may have already been destroyed by the increase in wave-induced loads due to the sea level rise which occurred during the life of the structure (FHWA 2016a). Sea level rise occurring between the time of the original design of the I-10 bridge near Pensacola Florida and the day that it was severely damaged during Hurricane Ivan, increased the wave-induced loads by roughly 70 kips; enough to lead to the catastrophic failure. In other words, if sea levels had not risen for the four decades prior to that storm, the bridge may have survived. Another finding is that most of the countermeasures suggested to increase bridge resilience to storm damage may not provide much actual benefit. Strengthening the connections between the decks and the substructure, which typically fail, will 
just lead to another failure mechanism slightly later in major storms - negative bending of the girders and decks due to the extreme, wave-induced uplift loads.

In many cases, coastal engineering works to protect roads and makes good economic sense with today's sea level. The economic argument is even stronger when considering sea level rise projections (FHWA 2016b).

It is clear that "adaptations" for climate resilience will be similar to engineering required for improving infrastructure resilience to extreme events with today's sea levels, i.e. existing, proven coastal engineering approaches including nature-based solutions (FHWA 2016c).

FHWA is developing other technical assistance for transportation agencies in related coastal engineering areas. For the FHWA, authors developed a "primer" on coastal modeling as an introduction to coastal hydrodynamic modeling for transportation engineering professionals (Webb 2017). Also, some of the authors produced a "white paper" describing the current state of practice regarding the use of natural and nature-based features to protect coastal roads (Webb, et al 2018). Finally, FHWA is conducting two separate series of "peer exchanges" to investigate and draw upon the knowledge of coastal transportation practitioners in the areas of natured-based infrastructure approaches and coastal nuisance flooding.

\section{UNIQUE COASTAL ENGINEERING TOOLS}

Particular coastal engineering approaches/tools and findings that have been developed through the efforts described above include guidance and findings on:

- Wave loads on bridge decks

- Assessing vulnerability of coastal roads to extreme events including climate change

- Engineering adaptations to coastal roads for improved resilience, and

- Nature-based solutions to coastal roads and bridges problems

PRESENTLY ONGOING REVISION OF HEC-25

As mentioned above, FHWA has engaged the authors to revise HEC-25 to combine the two existing volumes (see Figure 1) into a single third edition. The revision will update all of the current material and also include significant expansions/additions in several areas:

- Nature-based solutions (marshes, dunes, beaches, etc.)

- Issues related to future sea level rise including quantification of projections for increased "nuisance" flooding

PROFESSIONAL TRAINING: COASTAL ENGINEERING The FHWA has developed a related 3-day professional development short course based on HEC-25: $2^{\text {nd }}$ edition (National Highway Institute, 2008). This traveling course has been taught at locations from Hawaii to New England to hundreds of state and federal transportation agency staff and their consultants over the past decade. As an adult education, continuing education course, the focus is on active, "hands-on," learning and includes the use of a portable wave flume (see Figure 2) for participant exercises on wave mechanics, rock revetment design and to investigate and understand how waves on storm surge can impact bridge decks.

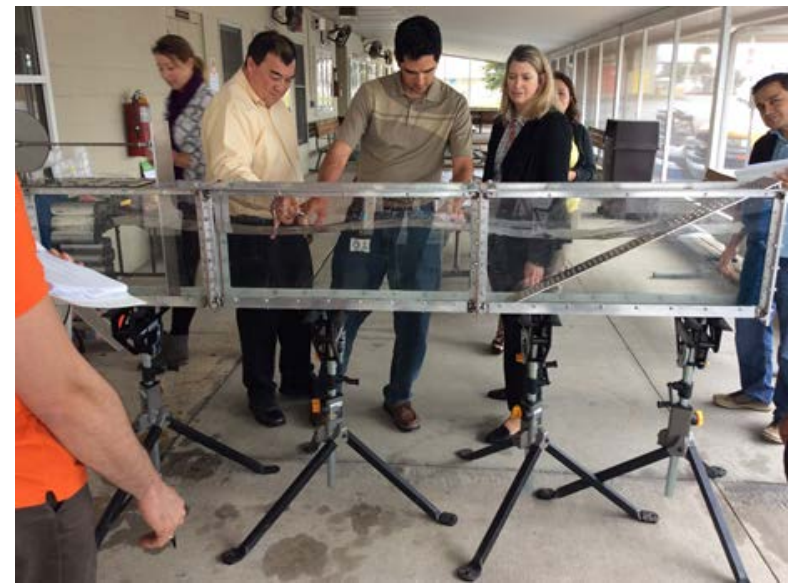

Figure 2. A portable wave flume being used by participants during a 3-day professional training course.

\section{REFERENCES}

FHWA (2008) Highways in the Coastal Environment, HEC-25, $2^{\text {nd }}$ ed., FHWA-NHI-07-096, 250 pp.

https://www.fhwa.dot.gov/engineering/hydraulics/pubs/07 096/07096.pdf

FHWA (2014) Highways in the Coastal Environment: Assessing Extreme Events, HEC-25, Vol. 2, NHI-14-006, $147 \mathrm{pp}$.

https://www.fhwa.dot.gov/engineering/hydraulics/pubs/nhi 14006/nhi14006.pdf

FHWA (2016a) Sea Level Rise and Storm Surge Impacts on a Coastal Bridge: I-10 Bayway, Mobile, AL, TEACR Engineering Assessment, FHWA HEP 17-014, 52 pp. https://www.fhwa.dot.gov/environment/sustainability/resil ience/ongoing and current research/teacr/al i-10/

FHWA (2016b) Barrier Island Roadway Overwashing from Sea Level Rise and Storm Surge: US 98 Okaloosa Island, FL, TEACR Engineering Assessment, FHWA HEP 17015, $32 \mathrm{pp}$.

https://www.fhwa.dot.gov/environment/sustainability/resil ience/ongoing and current research/teacr/fl us 98/

FHWA (2016c) Living Shoreline along Coastal Roadways Exposed to Sea Level Rise: Shore Road in Brookhaven, New York, TEACR Engineering Assessment, FHWA HEP 17-016, $29 \mathrm{pp}$.

https://www.fhwa.dot.gov/environment/sustainability/resil ience/ongoing and current research/teacr/ny shore ro ad/

National Highway Institute (2008) Highways in the Coastal Environment, Course No. 135082.

Webb, B.M. (2017) A Primer on Modeling in the Coastal Environment, FHWA-HIF-18-002, 71 pp.

Webb, B.M., S.L. Douglass, B. Dix, and S. Asam (2018) White Paper: Nature-Based Solutions for Coastal Highway Resilience, FHWA-HEP-18-037, 42 pp.

https://www.fhwa.dot.gov/environment/sustainability/resil ience/ongoing and current research/green infrastructur e/nature based solutions/ 